have been added on spondylolisthesis, scurvy, rickets, fotal rickets, progressive obliterative arteritis, and Raynaud's disease. In the account of the last affection we miss any reference to the intermittent hæmatinuria which has been observed in some of the recorded cases, and appears to be distinctly associated with the affection. In an appendix we have a short description of Strasburger's views of indirect cell multiplication illustrated by Ziegler's diagrams of cells in various stages of this process. This book has already commended itself so fully to students that it needs no recommendation from us, and we have only to congratulate Mr. Pepper upon his success and upon the improvements he has introduced into this edition.

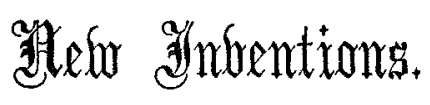

\section{AN IMPROVED TOURNIQUET.}

As considerable inconvenience has resulted to surgeons and dressers from the want of a good compressor and an easily-acting clip for the fixing or freeing of the elastic cord, I have recently introduced the following plan of a tourniquet for general use in the Westminster and other operating theatres. The subjnined drawing illustrates the tourniquet, as well as its application over the femoral artery. The elastic cord is fixed in the $\mathbf{T}$-shaped compressor by a concealed bullet in the cord, which prevents the cord pulling out one way only, but allows the cord to be withdrawn for purposes of cleanliness through a round hole at the base

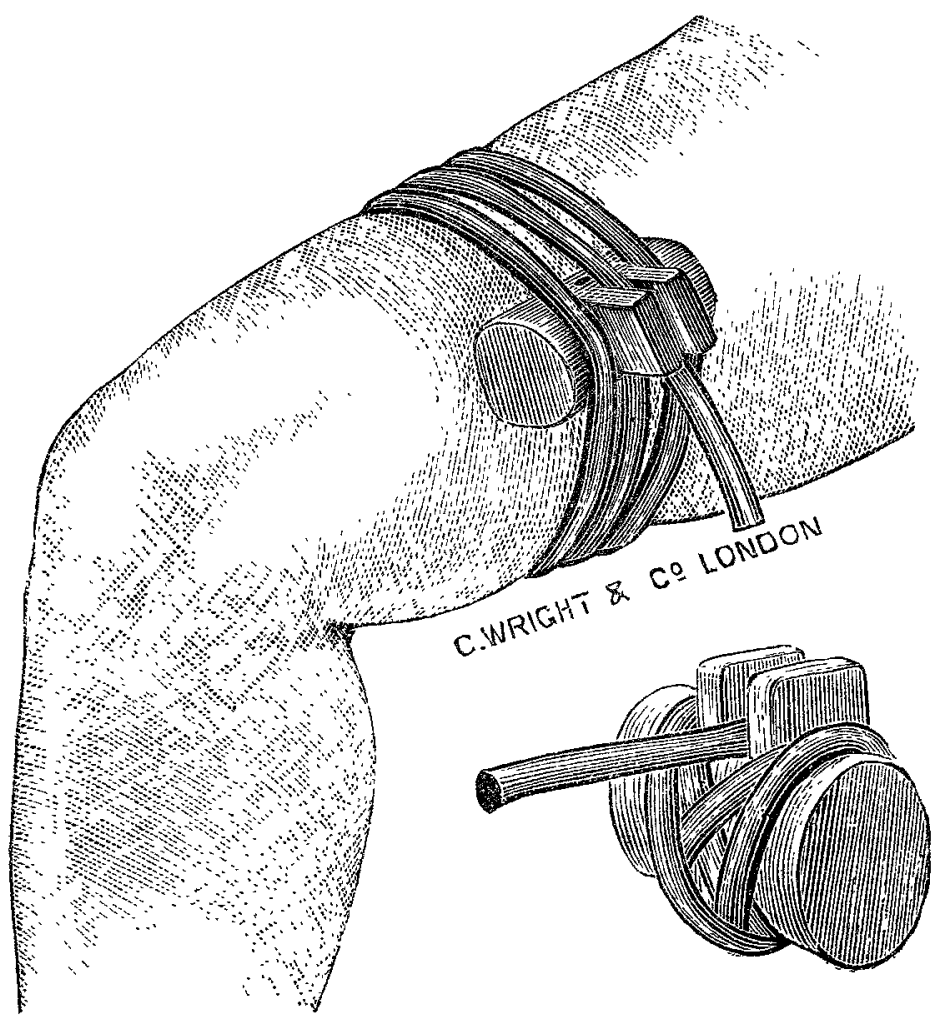

of the slot. This slot is cut deep in the handle of the $\mathbf{T}$, and the cord in a state of tension is most readily fixed or liberated, the act of letting the elastic cord go in the slot being sufficient to make it secure. The cord may be used either as a one-ended or double band. By allowing the elastic cord to wind over the arms of the $\mathbf{T}$, the compressor is nicely fixed for the use of the slot. This mechanism can be adjusted so tenderly that I have used a very small one for combating the nuisance of incontinence of urine, by applying the compressor under the urethra and the cord (doubly clipped) around the penis.

Messrs. Wright and Co., of 108, New Bond-street, W., are the makers. Although in amputations the skilled thumbs of an assistant may be very good, yet I renture to think that the utility of this mechanical arrangement may be proved in urgent and not infrequent occasions.

RICHARD DATY, M.B., F.R.S.E.,

Welbeck-street, Carendish-square, W. Surgeon to the Westminster Hospital.

\section{TOZER'S AMBULANCE STRETCHER.}

Mr. Tozen, Chief Superintendent of the Birmingham Fire Brigade, has devised a new form of ambulance stretcher for the removal of injured persons, which promises to be very useful, and at the same time convenient. The apparatus is

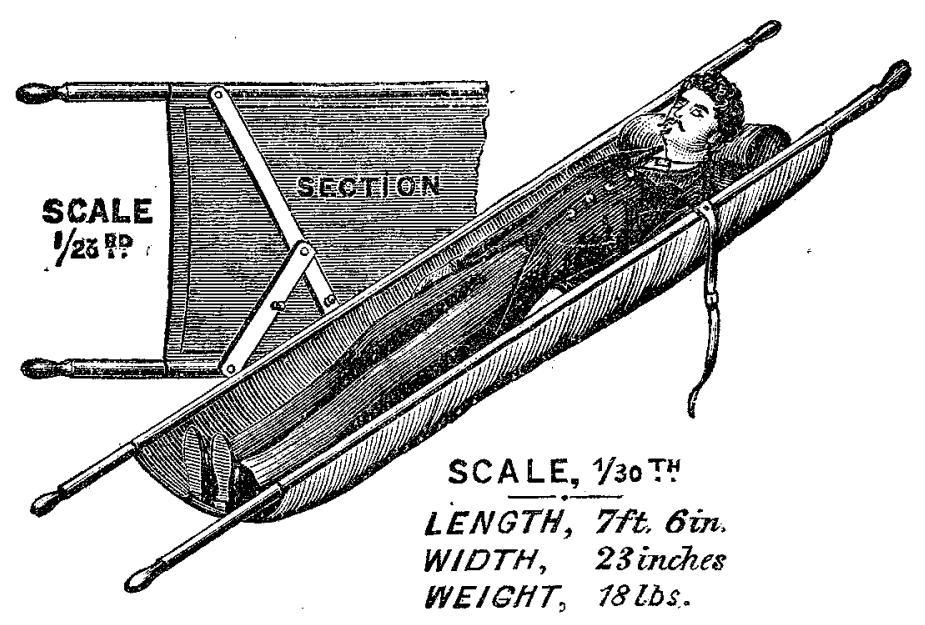

exceedingly simple - so much so as scarcely to need explanation, since the larger scaled section shows the method of opening and closing. The apparatus is inexpensive, and would be found serviceable in hospitals, police and fire brigade stations. The manufacturers are Messrs. Salt and Son, Corporation-street, Birmingham.

\section{"THE MIND."}

To the Editor of THE LANCET.

SIR,-In the appreciative and discriminating notice of $\mathrm{my}$ lecture on the Human Mind there is, I think, one point on which you rather misapprehended my meaning-namely, in reference to the doctrine of heredity: whether $I$ am right in thinking this is a matter of small importance. But as heredity is a question which occupies the public mind a good deal, and is really one of great importance, I trust I shall not be considered presumptuous in putting briefly before your readers (who are many of them far better instructed than I am with regard to the physiological aspect of the subject) what I really do mean. I agree with you in thinking that probably "when any species of organised matter reproduces its kind, the form in which it is cast is as much part of the inheritance as the matter itself, and it is on this form character and quality depend"; and also that "the education thus reproduced...... is the recorded result of function." I do not, however, quite like the word "recorded," inasmuch as it seems to imply (but perhaps I am wrong in supposing this) a memory of past occurrences, and $I$ do not see that anything of this kind is innate. For example, I should say that the progeny of an educated pointer is born probably with a greater capability of doing its work than a pointer not thus educated; but I do not believe that it is born with any knowledge of fields, partridges, \&c. I think that, when put in this light, you would not probably differ from my view. I venture to make these remarks, as I think that the more accurately we can bring before our minds the real nature of what we mean by an "educated" faculty in connexion with heredity, the more likely we are to get before us a clear issue, and to obtain valuable information on the subject.

I am, Sir, yours faithfully, Castle-hill. Ealing. July 8th, 1885.

S. J. JERRAM. 